\title{
The Component in Functional Structure of News Communication
}

\author{
Xiuhu Tan \\ Journalism Department, Chengdu Sport University, Chengdu, China \\ txhchinese@163.com
}

\begin{abstract}
The nature of sport news presents a set of opportunities for the application of stochastic modeling, which is able to apply statistical methods to describe and analyze the communication result of sport news entertainment. In this paper we provide an open framework that can be used to develop applications related to entertainment and news report in order to improve the communication result of sport news. Through the study of sports news entertainment feature of the various consumer groups, according to the transmission model, we put forward some theoretical principles and analyze the application misunderstandings of communication theory in sport domain, and improve the accuracy of data. The test result shows that the model can obtains empirical support in the application analysis.

Keywords: Media Streaming, Media, Communication.
\end{abstract}

\section{Introduction}

Olympic sports have promoted the rapid development of sports worldwide and achieved unprecedented success. While the sports are valued by the society, sports news has become a major focus of the mass media. Driven by the wave of cultural market entertainment, sports news reports also develop in the direction of entertainment. Sports news entertainment extends the traditional extension of sports news, and develops the content of reports to people, things, and objects etc. [1] related to the events from the sports events itself. On the one hand, sports news entertainment broadens the content and the scope of sports news, and increases interesting details, as well as expands the scope of the audiences; but on the other hand, sports news entertainment also prompts the media organizations to lean to soft news in the topic selection of sports news, which means that the focus of report is not laid on the sporting events themselves, but on the athletes.

The Analysis of the Relationship between Entertainment and Sports, Sports News

\section{Entertainment is the basic function of sports}


Sports itself have the natural properties of entertainment. Sports originate from activities and games of early humans in the leisure time, and are closely related to other social practice activities of the human society. From the beginning, sport is closely linked with the entertainment. Through the information on the sports history, we can find that sports also include many entertainment elements even in the primitive society. Even though the development of society, reform of the times and human progress have changed the form, the content and presentation of sports, the entertainment is always present in various sports in all ages. Sports, especially competitive sports, have the characteristic of timeliness, irritation and attractiveness due to the rapidly changing competition situation and uncertain results in the process of the competition, providing people with a healthy way of entertainment. People participate in the sports to do some exercise, and also to ease the mental stress during the work and life. By enjoying the sports events, the beauty of art showing in the sports make people get pleasure even without any packaging and modification. For example, French Open, one of the four top international tennis tournament and at the only clay court, admission ceremony of athletes has been simplified, and even there is not the conventional ceremony to introduce players; during the competition, in addition to the striking of tennis and the roar of athletes, there is the sound of the referee and the linesman; the competition has pause each round, and players change sides to rest, while audiences in the field are also silent; after the competition, the athletes as the winner do not need to accept on-site interviews. During the competition, except the occasional cheers and applause for the wonderful return, the audiences quietly enjoy the game, and get pleasure from sports competition. Compared with other games, the French Open lacks of entertaining elements. Although without the passionate performance of cheering squad for NBA, without the star of the show for the U.S. Major League Baseball opening ceremony, for the audience whether on-site or in front of the TV, this does not stop people from getting pleasure from the game, and the exciting game brings the audience a visual enjoyment and relaxation of body and mind (Fig 1). 


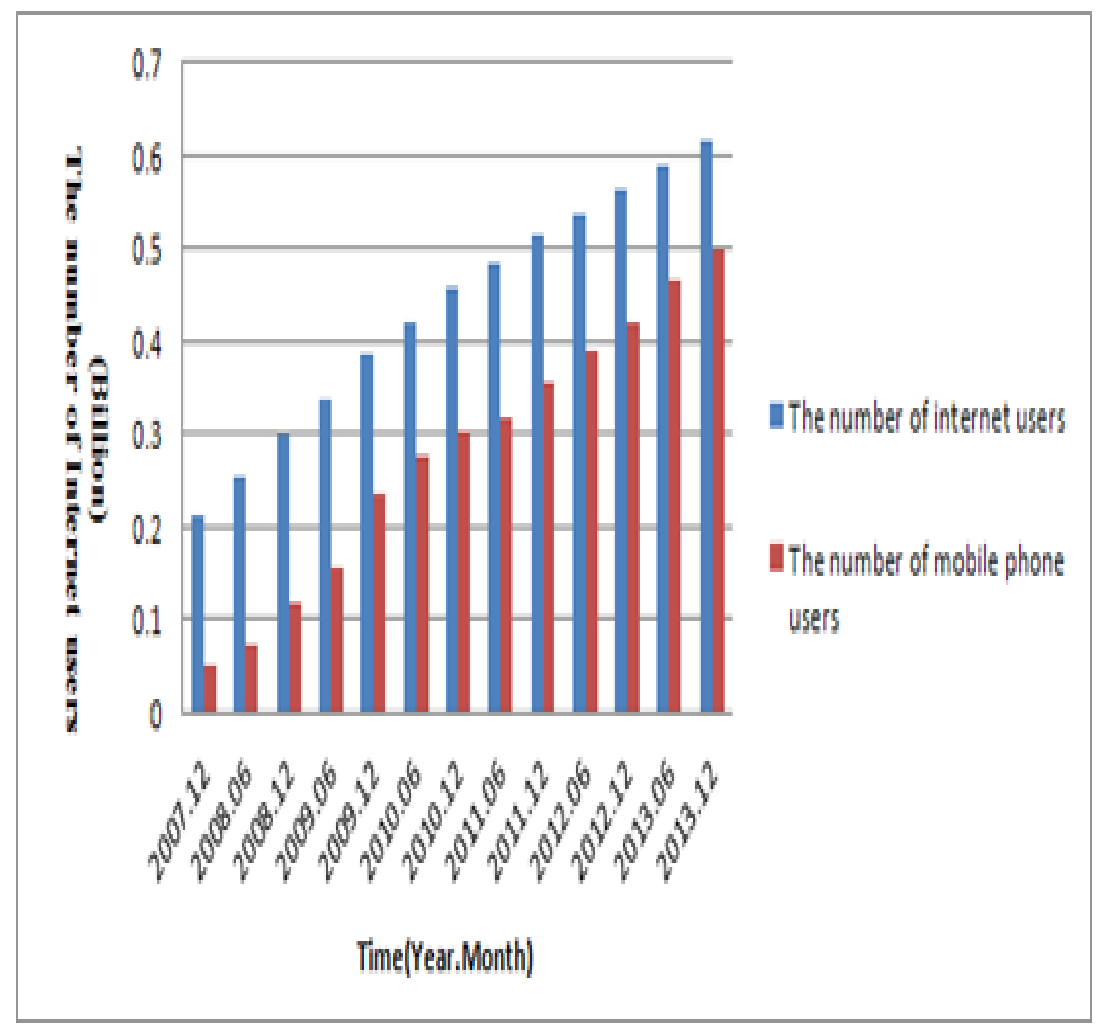

Fig 1 The Number of Mobile Phone Users

\section{Entertainment is not the main function of sports news}

From the results of the final victory, the information function of the news communication has defeated the entertainment function. As a category of news, in terms of the nature of the communication, sports news has a common characteristic with all kinds of news, that is, the reports on the facts occurring or are occurring recently [2]. From the main function of the news, the main function of sports news should be to spread the sports information.

From the perspective of content classification, sports events rebroadcasting belongs to sports news, or belongs to entertainment. There are different classification methods in different historical periods. In earlier practice of journalism, journalists regard sports events rebroadcasting as news rather than entertainment. From the perspective of the law, news reports do not need to pay, so the media organizations believe that broadcast rights of sporting events do not need to buy. However, in 1958, the International Olympic Committee amended Article 49 of "Olympic Charter", giving a clear definition of sports events broadcasting. The broadcasting of sporting events is not news, but entertainment, and it needs to be paid to broadcast sporting events. The revised Article 49 of the Charter also provides that news stations can broadcast the Olympics news, but the 
broadcasting of Olympic Games live content can not be more than 3 minutes each time, and re-broadcasting has to wait at least four hours[3]. In accordance with the provisions of the "Olympic Charter", the broadcasting of sports games does not belong to sports news.

\section{Market Economy Promotes Entertainment of Sports News}

Economic globalization has become an irreversible historical trend, under of which all industries are undergoing profound changes under the impact of marketization and commercialization, and the media industry is no exception. Media is the industry which opens to the market earlier, and the competition between the media would have been very intense. But from the beginning of the 1990s, on the one hand, with the changes of the world political situation, countries have successively relax the control and funding for the public media institutions, which makes a number of public medias move towards the market to carry out commercial operation, such as the British Broadcasting Corporation (BBC); on the other hand, due to the lower threshold, a large number of commercial media have joined the competition; in addition, the development of information technology promotes the rapid development of the new media such as online media, microblog, and micro-letter, which seizes the market share of traditional media. A variety of situations together make the competition of media market show an unprecedented level. In the market economy environment, in order to survive and develop, media organizations must be market-oriented, and firmly grasp the public's attention. Therefore, the tendency to make adjustments in the content topics and to choose the soft news with strong entertainment has become more apparent.

From the perspective of media communication, compared to the serious topics such as political, ethical and social responsibility, sports reports have fewer limitations and more conditions and qualifications to be entertained. Sports news is the product of the combination of sports and mass media. One of the social functions of the mass media in general is entertainment, and entertainment is the greatest common point of the public interests and interest demand [4]. In order to increase the influence of the media, media organizations continue to excavate the entertainment elements of sports and increase the reports outside the stadium, to track the life anecdotes of sports stars in order to attract the attention of audiences. Entertainment of sports news is the inevitable outcome due to the intense competition among the media under the market economy environment.

\section{Reflections on entertainment of sports}

\section{Limited role of entertainment for sports news}

Although entertainment plays a positive role in promoting the sports news media (also brings some negative effects), from the perspective of the sports news 
communication practices, because the sports news communication has its own particularity, entertainment plays a limited role in improving the influence of sports news, and the development of sport itself is the main factor to impact the communication of sports news. Taking sports of our country for example: Lin Dan involves in the entertainment industry, and Guo Jingjing has children as wll as Li Na divorce, etc. We can not say that the degree of entertainment in our country is not high. In present China, in addition to the Olympics, World Cup and other international top events and gossip about sports celebrity, as the main object of sports news reports, influence and attraction of domestic sports events can not be compared with the entertainment programs. Any domestic sporting events are difficult to match the audience rating and public participation of "I am a singer" and "Voice of China" and other entertainment programs. In order to enhance the influence and attract the audience, some domestic sports events have taken the approach of sports entertainment, but the achieved effect remains limited. For example, on June 22 of this year, Shenhua team and Harbin team had a game in Shanghai Hongkou Football Stadium, but the attendance of Hongkou Football Stadium is merely 10,245 people. And after just 48 hours, the "2013 Asian Dream Cup" charity football match in the same stadium attracted 24,000 soccer fans and singer fans because of the show and singing of Korean singer PSY, eighty percent of which are attracted by PSY's performances rather than the football game itself [5-6], so that the commercial competition blending in the entertainment element has created the attendance record of Hongkou Football Stadium for football game this season. Even worse, in the fifth round of Chinese Football Association Super League, Tianjin Teda competes against Qingdao Zhongneng at home court. Because the game runs into Wang Feng's concert, the number of people watching football matches is reduced by 7000. It is not merely the football game. In the eighth round of the CBA league last year, Shandong team competes against Fujian team at the home court. Due to the conflict with Na Ying's concert, Shandong team was forced to replace the home court. Compared to football and basketball, other sports with relatively poor mass base are unable to attract more audience. Based on this situation, sporting events organizers have to invite stars and singers to help out. Sporting events are the foundation and the main for the sports news. If sports events can not effectively attract the mass to watch the game in the stadium, it can only be futile to attract the audience by entertaining sports news. Although it may play a momentary role, it can not enhance the influence of sports news from the essence, so that raising the level of sports competition is the basis to solve the problem.

\section{Entertainment should adhere to the principle of objective truth}

As everyone knows, the origin of news is the fact. Authenticity is the basis for the news to gain the trust of audience. If there is no authenticity in the news, the news is losing its original value and meaning of the transmission. For the authenticity of the news, the United Nations journalists' qualities provide that: "staff of newspapers and other media shall make every effort to ensure that the public accept the absolutely correct message." News reports shall stick to the basic 
principle of facts first and news second. News report is objective facts which are reproduced by the journalists at the prerequisite of insisting the authenticity of the news through research, selection and analysis of information. The sports news needs to adhere to the authenticity of the news in the same way, and report sporting events and information in an objective and impartial manner. The information sources of sports news must be true, which shall reflect real phenomena and issues.

\section{Sports news entertainment shall keep degree}

Degree is a philosophical concept, which means a limit, scope and range of amount for the substance to maintain its nature. The occurrence and development of anything in the world are related to the degree. In the allowable range, nature of things remains unchanged; out of restrictions of degree, qualitative change of things will happen. It is possible for entertainment of news, but the key is the degree of entertainment in the news reports. If the degree is proper, the news will be close to nature, so as to win the favor of the audience and get a better result of communication; but if in the news programs, entertainment news excesses the number of serious news, or entertainment news is excessively packaged, it will weaken the information communication and the public supervision function of news, and make the news show a vulgar and pornographic trend.

With the continuous development of China's sports industry, the marketization and commercialization trend in sports news become more obvious, which shows excessive entertainment phenomenon. The publicity of sporting spirit that encourages people to make progress and reflects the light of humanity has encountered unprecedented challenge. The need and love for sports make the public transfer the attention to the sports news. In addition to a part of the audience watching the game live, most people know and understand the sports through sports news. On this basis, the love and criticism for the sports almost entirely depend on the sports news. Therefore, sports news shoulder the responsibility for the development of sports, and sports news reporters shall have sports human spirit and professional quality, not at the price of losing the value of news.

\section{Conclusion}

If the news media makes excessive entertainment news in the practice of sports news, which not only damages the social credibility of their own, but also has a negative impact on the development of sports. Sports news sports must adhere to the center of serving for the sports industry, the purpose of serving for the public, and play its due role for the dissemination of sports culture.

\section{References}

[1] Liang. Z, Haohong .W: IEEE Trans, Multimedia. Vol. 15(4) (2013), p. 735. 
[2] Sha. X Wang. D: IEEE Trans, Multimedia. Vol. 15(4) (2013), p. 870.

[3] Shaolei. R, Vander. SM: IEEE Trans, Multimedia. Vol.15(4) (2013), p. 723.

[4] Ali. T, Saquib. M: IEEE Trans, Digital Object Identifier. Vol. 12(3) (2013), p. 447.

[5] Xiong. S, Bogy: IEEE Trans, Magnetics. Vol. 50(3) (2014), p. 102.

[6] Maes. R, Schellekens. D: IEEE Trans, Information Forensics and Security. Vol. 7(1) (2012), p. 98. 